\title{
Dopant Incorporation Efficiency in CVD Silicon Carbide Epilayers
}

D. J. Larkin

NASA Lewis Research Center, MS 77-1, 21000 Brookpark Road, Cleveland, $\mathrm{OH} 44135$, U.S.A.

\begin{abstract}
In order to ensure reproducible and reliable $\mathrm{SiC}$ semiconductor device characteristics, controlled dopant incorporation must be accomplished. Some of the many factors which greatly influence dopant incorporation are the site-competition effect, $\mathrm{SiC}(0001)$ substrate polarity, substrate temperature, and the dopant-source reactor concentration. In this paper, dopant incorporation is considered and compared for various dopants in the context of dopant incorporation efficiency. By using secondary ion mass spectrometry (SIMS), the relative dopant incorporation efficiencies were calculated by dividing the SIMS determined dopant concentration in the resulting epitaxial layer by the intentional gas phase dopant concentration used during the $\mathrm{SiC}$ CVD. Specifically, the relative magnitudes of dopant incorporation efficiencies for nitrogen, phosphorus, and boron in $6 \mathrm{H}-\mathrm{SiC}(0001) \mathrm{Si}$-face epitaxial layers are compared as a function of the site-competition effect and the dopant-source reactor concentrations. This serves as a first approximation for comparison of the relative "doping potencies" of some common dopants used in SiC CVD epitaxial growth.
\end{abstract}

\section{INTRODUCTION}

Silicon carbide $(\mathrm{SiC})$ is a high temperature semiconductor material currently being pursued for applications in high temperature, high power, and high frequency electronics 15 . SiC electronic devices will find applications in aerospace vehicle control, aerospace power conditioning, space communications, as well as terrestrial control systems6-8. However, in order to ensure reproducible and reliable $\mathrm{SiC}$ semiconductor device characteristics, controlled dopant incorporation must be accomplished. Some of the many factors which significantly influence dopant incorporation in $\mathrm{SiC}$ epitaxial layer growth include the site-competition effect, the SiC substrate polarity (i.e. Si-face or C-face of the $\mathrm{SiC}(0001))$, substrate temperature, and the dopant-source reactor concentration. Site-competition epitaxy is a recently reported dopant incorporation control technique which allows control over dopant incorporation by adjusting the silicon-source/carbon-source flow ratio ( $\mathrm{Si} / \mathrm{C}$ ratio) into the $\mathrm{CVD}$ reactor during epitaxial layer growth 9 . For example, on both $6 \mathrm{H}-$ and $4 \mathrm{H}-\mathrm{SiC}(0001) \mathrm{Si}$-face substrates, nitrogen dopant incorporation was found to be proportional to the $\mathrm{Si} / \mathrm{C}$ ratio whereas phosphorus, boron, and aluminum dopant incorporation was inversely proportional to the $\mathrm{Si} / \mathrm{C}$ ratio used in the $\mathrm{CVD}$ reactor during epitaxial growth 10,11 . In addition to the site-competition effect, the SiC substrate polarity has also been recently reported to effect dopant incorporation 12, 13. For example, secondary ion mass spectrometry (SIMS) results from aluminum doping studies indicate that aluminum dopant incorporation on $\mathrm{C}$-face substrates is $50 \mathrm{X}$ less efficient compared to Si-face $6 \mathrm{H}-\mathrm{SiC}$ substrates ${ }^{13}$.

In this paper, dopant incorporation efficiency will be considered and discussed for phosphorus $(\mathrm{P})$ and nitrogen $(\mathrm{N})$ as n-type and boron $(\mathrm{B})$ as p-type dopants in context of the sitecompetition effect and dopant-source reactor concentrations. Dopant incorporation efficiency is defined here as the ratio of the SIMS determined dopant concentration incorporated into the SiC epitaxial layer divided by the gas phase dopant concentration used during epitaxial growth. Dopant incorporation efficiency, expressed as a percentage, is only a relative measure for comparing the "doping ability" for each dopant-source under similar growth conditions. The ultimate goal is to provide the reader with a first approximation of the various doping abilities in terms of the relative magnitudes of "reactor dopant concentrations" needed to accomplish a desired amount of dopant

337

Mat. Res. Soc. Symp. Proc. Vol. $410^{\circ} 1996$ Materials Research Society 
incorporation into a growing $\mathrm{SiC}$ epitaxial layer, as well as the relative impact of the sitecompetition effect on the incorporation of selected dopants derived from specific dopant sources.

\section{EXPERIMENTAL}

Commercially available $\mathrm{n}$-type $6 \mathrm{H}-(0001) \mathrm{SiC}$ Si-face boule-derived wafers ${ }^{14}$ were used as substrates for the $6 \mathrm{H}-\mathrm{SiC}$ epilayers which were grown in an atmospheric pressure CVD system 15 . 16, with a typical growth rate of $3 \mu \mathrm{m} / \mathrm{h}$. The SiC substrates were precleaned using a standard degreasing solution, followed by immersion in boiling sulfuric acid for 10 minutes, with a final deionized-water rinse and then dried with filtered nitrogen. The cleaned substrates were placed onto a SiC-coated graphite susceptor and then loaded into a water-cooled fused-silica reactor. The samples were heated via the RF-coupled susceptor which was temperature controlled at $1450^{\circ} \mathrm{C}$ using an optical pyrometer. Silane $\left(3 \%\right.$ in $\left.\mathrm{H}_{2}\right)$ and propane $\left(3 \%\right.$ in $\left.\mathrm{H}_{2}\right)$ were used as the sources for $\mathrm{SiC}$ epilayer growth, whereas a $90 \mathrm{sccm}$ flow of ultra-pure hydrogen chloride gas in a $3 \mathrm{sLpm}$ flow of hydrogen was used during a $1350^{\circ} \mathrm{C}$ in situ etch prior to epilayer growth. All gases were mass flow controlled, including the ultra-pure hydrogen carrier-gas which was purified by using a heated-palladium diffusion cell. The epilayers were doped $n$-type using either phosphine or nitrogen and p-type using diborane. For comparison of nitrogen and phosphorus dopant incorporation efficiencies, experiments were performed using similar flows of equivalent atomic source-concentrations of phosphorus $\left(2 \% \mathrm{PH}_{3}\right.$ in $\left.\mathrm{H}_{2}\right)$ and nitrogen $\left(1 \% \mathrm{~N}_{2}\right.$ in $\left.\mathrm{H}_{2}\right)$. Similarly, equivalent atomic source-concentrations of boron $\left(100 \mathrm{ppm} \mathrm{B}_{2} \mathrm{H}_{6}\right.$ in $\mathrm{H}_{2}$ ) and phosphorus (200 ppm $\mathrm{PH}_{3}$ in $\mathrm{H}_{2}$ ) were used for dopant incorporation efficiency comparisons. Secondary ion mass spectrometry (SIMS) was performed 17 using a CAMECA IMS-4f double-focussing, magnetic sector ion microanalyzer, using implanted SiC standards. Cesium bombardment was used for determination of boron, phosphorous, and nitrogen atomic concentration profiles by using the detector in a negative secondary ion detection mode to monitor $\mathrm{P}$ - and the diatomic species $\mathrm{B}(+\mathrm{C})$ and $\mathrm{N}(+\mathrm{C})-$, respectively.

\section{RESULTS AND DISCUSSION}

For the following discussions, "dopant incorporation efficiency" is defined as the percentage of dopant which was incorporated into the grown epilayer compared to the amount (atomic concentration) which was available in the reactor during the SiC epilayer growth, calculated using equations (1) and (2):

$$
[\text { Dopant }]_{\mathrm{ppm}}=[\text { Dopant }]_{\mathrm{cm}^{-3}} /\left(\rho_{\mathrm{SiC}}\right)
$$

Equation (1) is used to convert concentrations of atoms $/ \mathrm{cm}^{3}$ into parts-per-million (ppm). With [Dopant $]_{\mathrm{ppm}}$ and [Dopant $\mathrm{cm}_{\mathrm{cm}^{-3}}$ as the SIMS determined dopant concentrations in ppm and

atoms $/ \mathrm{cm}^{3}$, respectively, and $\left(\rho_{\mathrm{SiC}}\right)$ as the density of $6 \mathrm{H}-\mathrm{SiC}\left(4.73 \times 10^{22}\right.$ atoms $/ \mathrm{cm}^{3}$, converted from $3.217 \mathrm{~g} / \mathrm{cm}^{3}$ ). Then the dopant incorporation efficiency is simply calculated by using:

$$
\mathrm{E}=\left([\text { Dopant }]_{\mathrm{SiC}} /[\text { Dopant }]_{\text {Reactor }}\right) \times 100
$$

Where $E$ is the calculated incorporation efficiency, and [Dopant $]_{\mathrm{SiC}}$ is the SIMS determined atomic dopant concentration in the epitaxial layer whereas [Dopant $]_{\text {Reactor }}$ is the gas phase atomic concentration of dopant available in the CVD reactor, both expressed in ppm. Note that the incorporation efficiency is multiplied by 100 to provide a more manageable range of values for ease of comparison and therefore expressed in percentages. 
As already stated, comparisons of dopant incorporation efficiency must be considered in context of the dominant factors which influence dopant incorporation during $\mathrm{SiC}$ epilayer growth. Previous reports document that dopant incorporation can be controlled by appropriately adjusting the silicon-source/carbon-source ratio ( $\mathrm{Si} / \mathrm{C}$ ratio) contained in the growth reactor during epilayer growth, which is more simply referred to as site-competition epitaxy9, 10. Additionally, this dopant control technique was reported to function independently of the substrate polytype based on similar results of dopant control obtained for $6 \mathrm{H}, 4 \mathrm{H}$ and $3 \mathrm{C}-\mathrm{SiC}$ epilayers. Therefore, the following results of dopant incorporation efficiency will be considered in the context of the site-competition effect and dopant source concentration in the CVD reactor during epitaxial $6 \mathrm{H}-\mathrm{SiC}(0001)$ $\mathrm{Si}$-face growth, but equally apply for the $4 \mathrm{H}$ polytype.

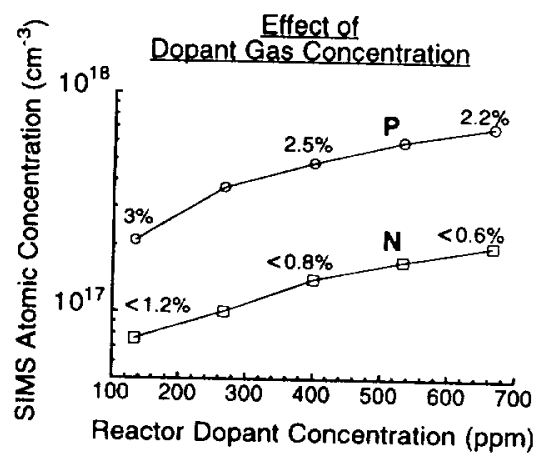

\section{Phosphorus versus Nitrogen Doping Efficiency}

For the following series of doping

Figure 1 Si-face phosphorus (P) versus nitrogen $(\mathrm{N})$ incorporation efficiencies calculated from using SIMS determined epilayer dopant concentrations divided by the corresponding reactor dopant concentration, while maintaining constant reactor concentrations of $\mathrm{Si}(200 \mathrm{ppm})$ and $\mathrm{C}(1050$ experiments the silane and propane flow into $\mathrm{ppm})$, resulting in a constant $\mathrm{Si} / \mathrm{C}$ ratio $=0.19$.

the reactor were maintained constant and only the dopant flow was increased within each series of epilayer doping experiments. The calculated dopant concentration (atomic) intentionally introduced into the reactor is plotted versus the SIMS determined dopant concentration (atomic) incorporated into the epitaxial layer (see Figure 1). The dopant incorporation efficiency is calculated according to equation (1) and (2). For example, referring to the $2.5 \%$ incorporation efficiency results for phosphorus shown in Figure 1, the SIMS determined phosphorus $(P)$ concentration is first converted into $\mathrm{ppm}$ by dividing the SIMS $\mathrm{P}$ concentration $\left(\mathrm{P}=4.8 \times 10^{17}\right.$ atoms $\left./ \mathrm{cm}^{3}\right)$ by the density of $6 \mathrm{H}-\mathrm{SiC}\left(\rho=4.73 \times 1022\right.$ atoms $\left./ \mathrm{cm}^{3}\right)$. The $P$ doping efficiency $(2.5 \%)$ was then obtained by dividing this SIMS P concentration $(10.1 \mathrm{ppm})$ by the gas phase concentration of $P$ in the CVD reactor $(400 \mathrm{ppm})$ during epitaxial growth For these Si-face epilayers, grown using a reactor concentration of $\mathrm{Si}=200 \mathrm{ppm}$ and $\mathrm{C}$
$=1050 \mathrm{ppm}(\mathrm{Si} / \mathrm{C}=0.19)$, the SIMS determined phosphorus $(\mathrm{P})$ and nitrogen $(\mathrm{N})$ epilayer concentrations increase as the dopant flow was increased for each epilayer growth-experiment in a series. In contrast, as the reactor dopant concentration was increased, the calculated dopant incorporation efficiencies decrease from $3 \%$ to $2.2 \%$ for $\mathbf{P}$ and from $<1.2 \%$ to $<0.6 \%$ for $N$. This incorporation efficiency decrease is consistent with a decrease in available substitutional lattice sites on the $\mathrm{SiC}$ growth surface, as the reactor dopant concentration is increased for both $\mathrm{P}$ and $N 18$. The more efficient $P$ incorporation increases from $2 \times 10^{17} \mathrm{~cm}^{-3}$ to $7 \times 10^{17} \mathrm{~cm}^{-3}$ compared to the less efficient $N$ incorporation which increases from $8 \times 1016 \mathrm{~cm}^{-3}$ to $2 \times 1017 \mathrm{~cm}^{-3}$ with equivalent increases in reactor dopant concentrations. The more efficient $P$ incorporation compared to $N$ is somewhat unexpected, especially when considering the much larger atomic size of $P$ compared to that of $N$. Specifically, the non-polar covalent radius for $P$ is $1.10 \AA$ compared to the $33 \%$ smaller size of the $N$ atom $(r=0.74 \AA) 19$. However, also by using atomic size as a first approximation (i.e. by neglecting chemical bonding arguments), $N$ should substitute for $C(r=0.77 \AA)$ whereas $P$ $(r=1.10 \AA)$ should substitute for $\mathrm{Si}(\mathrm{r}=1.17 \AA)$ in the $\mathrm{SiC}$ lattice, which is consistent with previous reports 20,21 . This argument leads to the idea that the amount of available Si-lattice sites (Si-sites) are greater than the amount of available C-lattice sites (C-sites) when using a relatively C-rich $\mathrm{Si} / \mathrm{C}$ ratio (e.g. $\mathrm{Si} / \mathrm{C}=0.19$ ), resulting in greater $\mathrm{P}$ incorporation because of the relatively morc 
abundant Si-sites compared to the amount of available C-sites. Therefore the site-competition effect (i.e. $\mathrm{Si} / \mathrm{C}$ ratio effect) must be carefully considered when comparing incorporation efficiencies.

The importance of the site-competition effect can best be illustrated by considering the data presented in Figure 2 in which only the reactor carbon concentration was increased in each successive experiment while the $\mathrm{Si}$ (200 $\mathrm{ppm}), \mathrm{P}(200 \mathrm{ppm})$, and $\mathrm{N}(200 \mathrm{ppm})$ were each maintained constant in the CVD growth reactor during separate $P$ and $N$ doping experiments. The intentional reactor carbon concentration is plotted versus the SIMS determined atomic concentration of dopant incorporated during the $\mathrm{SiC}$ epilayer growth. The calculated $\mathrm{N}$ incorporation efficiency abruptly decreases from $37 \%$ to $<1.9 \%$ as the reactor carbon concentration increases from $450 \mathrm{ppm}$ to $750 \mathrm{ppm}$ (Figure 2). However, note that the $\mathrm{N}$ efficiency is much greater than the $P$ efficiency at $C=450 \mathrm{ppm}^{18}$. Therefore, if the somewhat arbitrary reactor carbon concentration of $\mathrm{C}=450 \mathrm{ppm}(\mathrm{Si} / \mathrm{C}=0.44)$ had been chosen for experiments of Figure 1 instead of $\mathrm{C}=1050 \mathrm{ppm}(\mathrm{Si} / \mathrm{C}=0.19)$, then the $\mathrm{P}$ efficiencies. This Cite-competition effect. In this variation of dopant incorporation with $\mathrm{Si} / \mathrm{C}$ ratio is katio decreases because of the increased $\mathrm{C}$ case, the $\mathrm{N}$ incorporation decreases as the $\mathrm{Si} / \mathrm{C}$ ratio decreases because of the $\mathrm{P}$ and $\mathrm{N}$ dopant competition with $\mathrm{N}$ for available $\mathrm{C}$-sites. This ticaches that comparisons of $\mathrm{P}$. $\mathrm{C}$ ratios and cannot be generalized unless incorporation efficiencies are only valid for specific

the dominant site-competition effect is also considered.

In contrast, the $\mathrm{P}$ incorporation efficiency steadily increases from $2.4 \%$ to 8 . but unlike reactor $\mathrm{C}$ concentration is increased. This is also caused by the site-competition effect, but unlike $\mathrm{N}$ which is excluded from available $\mathrm{C}$-sites as the reactor $\mathrm{C}$ concentration is increased, $\mathrm{P}$ incorporation increases because of the increased availability of $\mathrm{Si}$-sites with increased reactor concentration. In comparing the P doping results shown in Figure 2 with those of Figure 1 , note that the calculated $P$ efficiencies of Figure 2 are mostly greater than those of Figure 1 whereas both have similar ranges of SIMS determined dopant incorporation. Therefore, if a phosphorus doped $\mathrm{SiC}$ epitaxial layer of $\mathrm{P}=8 \times 10^{17} \mathrm{~cm}^{-3}$ was desired, the conditions of Figure $1(\mathrm{C}=10 \mathrm{c}$. $670 \mathrm{ppm}$ ) would result in only a $2.2 \%$ efficiency compared to a $8.3 \%$ efficiency for the growth conditions of Figure $2(C=1950 \mathrm{ppm} ; P=200 \mathrm{ppm})$. In other words, $\mathbf{P}>3 \mathrm{X}$ decreased reactor $\mathrm{P}$ concentration could be used to produce an identical $\mathrm{P}$-doped epitaxial layer, which could be important for minimizing potential dopant memory effects, as well as residual contaminant effects, in CVD reactors. These results clearly confirm that $\mathrm{N}$ competes with $\mathrm{C}$ for $\mathrm{C}$-sites and $\mathrm{P}$ competes with $\mathrm{Si}$ for Si-sites.

\section{Phosphorus versus Boron Doping Efficiency}

The dopant incorporation experiments for boron were compared to those for phosphorus using a lower range of reactor dopant concentrations because of the relatively high $B$ incorporation efficiency. For these first series of $\mathrm{Si}$-face epilayer doping experiments, the intentional reactor effeiency. For the $\mathrm{Si}(200 \mathrm{ppm})$ and $\mathrm{C}(1800 \mathrm{ppm})$ were maintained constant during the growth of concentration of $\mathrm{Si}(200 \mathrm{ppm})$ and $\mathrm{C}(1800 \mathrm{ppm})$ were maintained constration of dopant was increased. The gas phase 
reactor dopant concentrations (atomic) versus the SIMS determined $B$ and $P$ epilayer concentrations are plotted in Figure 3. The plot with the greater SIMS determined B incorporation (for $C=1800 \mathrm{ppm}$ ) does not vary significantly $\left(4-5 \times 10^{19} \mathrm{~cm}^{-3}\right)$ with increasing reactor $B$ concentration. This first series of $B$ doping experiments have a maximum calculated $\mathbf{B}$ incorporation efficiency of approximately $86,000 \%$. In contrast, the corresponding maximum $\mathrm{P}$ incorporation is approximately $5000 \mathrm{X}$ less efficient $(17 \%)$, compared to this $B$ efficiency which experienced identical CVD growth conditions. In addition, as the reactor concentration of $P$ is increased, the SIMS determined $P$ incorporation also increases whereas the calculated $\mathrm{P}$ incorporation efficiency decreases (from $17 \%$ to $13 \%$ ) as did the previously discussed results using relatively greater $P$ reactor concentrations shown in Figure 1 . However, as the reactor concentration of $B$ is increased $(C=1800 \mathrm{ppm})$, the SIMS determined $\mathrm{B}$ incorporation remains relatively constant and therefore the $B$ efficiency decreases with increasing reactor $B$ concentration. It is postulated that this SIMS determined B concentration is approximately at the B solubility limit for these particular CVD growth conditions.

Results for the second series of $B$ doping experiments of Figure 3, using a relatively lower carbon concentration $C=450 \mathrm{ppm}$ (lower $B$ plot in Figure 3 ), were compared to the first series (upper B plot in Figure 3) which experienced a greater reactor $C$ concentration $(C=1800 \mathrm{ppm})$ the Si/C ratio, consistent with the site-competition effect, where the $\mathrm{B}$ mainly competes for the Si-site during the SiC epitaxial growth 11. Note that as the reactor $B$ concentration was increased (for $C=450$ $\mathrm{ppm}$ ), the $\mathrm{B}$ incorporation monotonically increases as does the calculated $B$ incorporation efficiency which increases from $270 \%$ to $1700 \%$. This increase in B incorporation with increased reactor $B$ concentration is consistent with the previously discussed $N$ and $P$ results. However, more work is needed in order to explain why the $B$ incorporation should increase so quickly with increased reactor $B$ that the B efficiency actually increases, which in contrary to the efficiency trend observed for $N$ and $P$.

The greater dopant incorporation efficiency for $\mathrm{B}$ for $\mathrm{C}=1800$ compared to $\mathrm{C}=$ 450 in Figure 3 , as a result of a relatively greater $\mathrm{C}$-source concentration relative to the Si-source concentration (i.e. a decreased $\mathrm{Si} / \mathrm{C}$ ratio), serves to illustrate the dominance of the site-competition effect on dopant incorporation

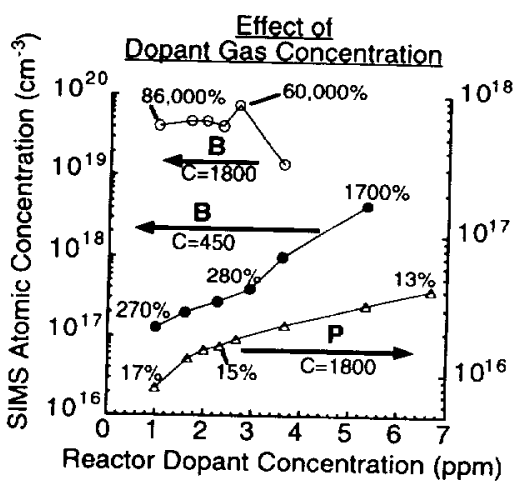

Figure $3 \mathrm{Si-face}$ boron (upper B plot) compared to phosphorus (P) incorporation efficiencies using constant $\mathrm{C}=1800 \mathrm{ppm}(\mathrm{Si}=200 \mathrm{ppm})$ dopant concentration increasing the reactor The lower boron plot performed using $\mathrm{C}=450 \mathrm{ppm}(\mathrm{Si}=200$ $\mathrm{ppm}$ ) during epilayer growth.

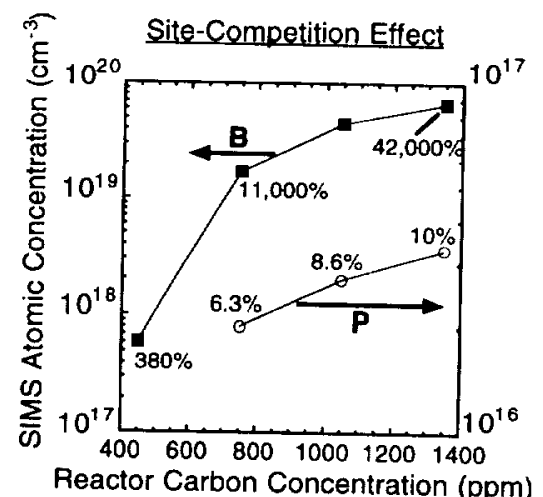

Figure 4 Si-face SIMS determined B compared to $\mathrm{P}$ incorporation efficiencies. The $\mathrm{B}(3.3$ $\mathrm{ppm})$ and $\mathrm{P}(6.6 \mathrm{ppm})$ reactor concentrations were constant while the $\mathrm{Si} / \mathrm{C}$ ratio was decreased by increasing the reactor carbon concentration. 
efficiency. The dominance of the site-competition effect is further illustrated by the lack of an increase in B incorporation which is normally expected for increased reactor B concentrations (upper B plot in Figure 3). This situation may also be encountered when using uncoated (or insufficiently SiC-coated) graphite susceptors or heated graphite reactor parts in a hydrogen atmosphere, resulting in significantly large concentrations of unintentional $\mathrm{C}$-species in the reactor, produced from the high temperature etching effect of hydrogen on graphite 22.

The $\mathrm{B}$ incorporation efficiency was also compared to the $\mathrm{P}$ efficiency as a function of increasing the reactor carbon concentration (i.e. $\mathrm{Si} / \mathrm{C}$ ratio) to determine the relative magnitude of the site-competition effect, as plotted in Figure 4. For each dopant series, the intentional reactor concentrations of $P(6.6 \mathrm{ppm}), \mathrm{B}(3.3 \mathrm{ppm})$, and $\mathrm{Si}(200 \mathrm{ppm})$ were maintained constant during growth of the $\mathrm{SiC}$ epilayers. The $\mathrm{P}$ incorporation efficiency increases with increasing reactor carbon concentration, with a maximum $P$ incorporation efficiency value of $10 \%$ (for $C=1350 \mathrm{ppm}$ and $P=6.6 \mathrm{ppm}$ ) as shown in Figure 4. This value is comparable to the $P$ incorporation efficiency of $13 \%$ (for $C=1800 \mathrm{ppm}$ and $\mathrm{P}=6.6 \mathrm{ppm}$ ) from Figure 3, which exhibits a slightly greater $P$ efficiency because of the greater site-competition effect resulting from the relatively greater reactor $C$ concentration used during CVD. As shown in Figure 4, the $B$ incorporation is much greater than $P$ incorporation despite the decreased reactor concentration of $B(3.3 \mathrm{ppm})$ compared to $P$ $(6.6 \mathrm{ppm})$ used during these separate doping experiments. In addition, the $\mathrm{B}$ incorporation Phich represents more than a $100 \mathrm{X}$ increase in $\mathrm{B}$ efficiency increase efficiency from only a $3 X$ increase (from $C$ concentration. The much geartially rationalized by for both constant (Figure 3 ) and varied (Figure 4) $\mathrm{Si} C$ ras, considering the relatively small atomic size of the $\mathrm{B}$ to substitute for $\mathrm{Si}(\mathrm{r}=1.17 \mathrm{~A})$ into the Si-site of the growing $\mathrm{SiC}$ epitaxial layer. 19

\section{CONCLUSION}

The dopant incorporation efficiency, defined as the ratio of the resulting epitaxial layer dopant concentration divided by the gas phase dopant concentration, was used as a relative measure for comparison of doping efficiencies for phosphine $(\mathrm{P})$, nitrogen $(\mathrm{N})$, and diborane $(\mathrm{B})$ as dopants that are typically used during the $\mathrm{CVD}$ of $\mathrm{SiC}$ epitaxial layers. Some of the factors that were discussed, and which influence dopant incorporation efficiency in the CVD growth of SiC epitaxial layers, include the site-competition effect ( $\mathrm{Si} / \mathrm{C}$ ratio) and the dopant source concentration in the reactor during CVD.

These results indicate that dopant incorporation efficiency for the $6 \mathrm{H}-\mathrm{SiC}(0001)$ Si-face epilayers ane greatly dependent upon the site-competition effect (i. C C-source concentration relative to the $\mathrm{Si}$-source concentration in the reactor during $\mathrm{SiC}$ epitaxial growth). The $\mathrm{P}$ and $\mathrm{B}$ dopant efficiencies increase whereas $\mathrm{N}$ efficiencies decrease with an increasing reactor incorpor concentration (i.e. decreasing the $\mathrm{Si} / \mathrm{C}$ ratio). This is explained by considering that both $\mathrm{P}$ 列 and $B$ occupy the Si-sites and that decreased by increasing the reactor $C$ concentration. Simlarly, the increase in competition from decrease as the reactor $C$ concentratio

$\mathrm{C}$ with the $\mathrm{N}$ for available $\mathrm{C}$-sites. For example, a $3 \mathrm{X}$ increase in the reactor carbon concentration (450 $40 \mathrm{X}$ decrease in $\mathrm{N}$ resulted in an approximate $100 \mathrm{X}$ increase in $\mathrm{B}$ effecte (Figure 2). This notable change in doping efficiency (Figure 2), and a $2 \mathrm{X}$ increase in P efficiency (Figure 2). This notate-competition effect, efficiency with a changing $\mathrm{Si} / \mathrm{C}$ ratio during epitaxial growh, known as be considered in order to greatly influences dopant incorporation efforion in the growth of SiC CVD epitaxial layers.

obtain valid interpretations of dopant incorporation in the growth of SiC C
For constant $S$ i-source and $C$-source reactor concentration ratios, as each respective dopant concentration into the reactor was increased, the dopant incorporation efficiencies decrease for $N$ and $\mathrm{P}$, but increase for $\mathrm{B}$. This was partially rationalized by considering the relatively small atomic size of the $B$ atom (radius $=0.82 \AA)$ compared to that of $P(r=1.10 \AA$ ) greater ability of $B$ to substitute for $S i(r=1.17 \AA)$ 
layer. 19 However, more work is needed to fully understand the reasons for these incorporation efficiency differences.

\section{ACKNOWLEDGMENTS}

The author would like to acknowledge Luann J. Keys and Andrew J. Trunek for their expertise in performing the CVD experiments. This work was supported through internal NASA funding.

\section{REFERENCES}

1P. G. Neudeck, Journal of Electronic Materials, 24 (4), 283-288 (1995).

2B. J. Baliga, IEEE Spectrum, 32 (7), 34-49 (1995)

3B. J. Baliga, Microelectronic Engineering, 28 (1-4), 177-184 (1995).

4M. Bhatnagar and B. J. Baliga, IEEE Trans. Electron Devices, 40 (3), 645-655 (1993).

5C. E. Weitzel, IEEE Electron Device Lett., 16 (10), 451-453 (1995).

${ }^{6} \mathrm{C} . \mathrm{M}$. Carlin and J. K. Ray, in Second International High Temperature Electronics Conference, edited by D. B. King and F. V. Thome (Charlotte, NC, 1994), p. I-19 to I-26.

7S. J. Przybylko, American Institute of Aeronautics and Astronautics from Washington, DC (1993).

8W. C. Nieberding and J. A. Powell, IEEE Trans. on Industrial Electronics, 29 (2), 103-106 (1982).

9D. J. Larkin, P. G. Neudeck, J. A. Powell, and L. G. Matus, Appl. Phys. Lett., 65 (13), 1659 1661 (1994).

10D. J. Larkin, P. G. Neudeck, J. A. Powell, and L. G. Matus, in Silicon Carbide and Related Materials: Proceedings of the Fifth International Conference, edited by M. G. Spencer, et al. (IOP Publishing, Bristol, United Kingdom, 1994), Institute of Physics Conference Series, No. 137, p. 51-54.

11D. J. Larkin, S. G. Sridhara, R. P. Devaty, and W. J. Choyke, Journal of Electronic Materials, 24 (4), 289-294 (1995).

12T. Kimoto, A. Itoh, and H. Matsunami, Appl. Phys. Lett., 67 (16), 2385-2387 (1995).

13D. J. Larkin, in 6th International Conference on Silicon Carbide and Related Materials, (Kyoto, Japan, 1995).

14Cree Research, Inc., 2810 Meridian Parkway, Suite 176, Durham, NC.

15J. A. Powell, L. G. Matus, and M. A. Kuczmarski, J. Electrochem. Soc., 134 (6), 1558-1565 (1987).

16J. A. Powell, D. J. Larkin, L. G. Matus, W. J. Choyke, J. L. Bradshaw, L. Henderson, M. Yoganathan, J. Yang, and P. Pirouz, Appl. Phys. Lett., 56 (15), 1442-1444 (1990). 
17SIMS Charles Evans \& Associates, 301 Chesapeake Drive, Redwood City, CA.

18NOTE (It should be noted, however, that this $N$ incorporation efficiency represents an upper bound because of the potentially significant atmospheric-N background contributions for these SIMS determined epilayer concentrations of $N$ in the $<1-2 \times 1017 \mathrm{~cm}^{-3}$ range).

${ }^{19}$ K. F. Purcell and J. C. Kotz, Inorganic Chemistry, (W. B. Saunders Co., Philadelphia, PA, 1977).

20R. F. Davis and J. T. Glass, The Growth and Characterization of Silicon Carbide and Diamond for Microelectronic Applications, in Advances in Solid-State Chemistry, C. R. A. Catlow, Editor. 1991, JAI Press Ltd.: London. p. 1-111.

21W. J. Choyke, , in The Physics and Chemistry of Carbides, Nitrides, and Borides. 1990, Kluwer: Dordrecht. p. 863 -

22S. Karmann, L. D. Cioccio, B. Blanchard, T. Ouisse, D. Muyard, and C. Jaussaud, Materials Science and Engineering B, B29, 134-137 (1995). 